\title{
Paid Sick Leave as a Means to Reduce Sickness Presenteeism Among Physicians
}

\section{Ingrid Steen Rostad}

PhD candidate, Norwegian University of Science and Technology, Department of Psychology, Norway

\section{Ann Fridner}

Associate Professor, Stockholm University, Department of Psychology, Sweden

\section{Marie Gustafsson Sendén}

Associate Professor, Stockholm University, Department of Psychology, Sweden

\section{Lise Tevik Løvseth'}

Researcher, St Olavs University Hospital, Department of Research and Development, Norway

\begin{abstract}
Recurrent international data show that physicians often attend work while ill, termed sickness presenteeism. The current study investigated if sickness presenteeism scores among European physicians varied according to national paid sick leave legislation. We hypothesized that prevalence of presenteeism was higher in countries with lower levels of paid sick leave. We used repeated cross-sectional survey data, phase I (2004/2005, N = 1326) and phase II (2012/2013, $N=1403)$, among senior consultants at university hospitals in Sweden, Norway, and Italy. Analyses of variances assessed cross-country differences in presenteeism. To assess the impact of country on presenteeism, we used multiple regression analyses controlled for sex, age, family status, work hours, and work content. The results from phase I supported the initial hypothesis. At phase II, presenteeism scores had decreased among the Italian and Swedish sample. The results are discussed with regard to changes in legislation on workhours and medical liability in Italy and Sweden between phase I and II.
\end{abstract}

\section{KEYWORDS}

Economic compensation / paid sick leave / physicians / sickness presenteeism / the HOUPE study / welfare benefits

DOI

To be announced

\section{Introduction}

n many countries, paid sick leave is an important means for improving employee health and organizational productivity. Societies aim to sustain the productivity of their human resources by enabling workers to access medical care and follow the

\footnotetext{
${ }^{1}$ E-mail: lise.lovseth@ntnu.no.
} 
recommended treatment to facilitate faster recovery and illness prevention. This is done by providing economic compensation for work days lost to worker illness through social health insurance or national health systems (Heymann et al., 2010; Lovell, 2004; ScheilAdlung \& Sandner, 2010).

Despite economic compensation for sick leave, many employees occasionally attend work when unwell, termed presenteeism (Johns, 2010). This behavior is prevalent among employees within the educational sector and the health and welfare services (Aronsson et al., 2000), and is particularly seen among physicians. International studies have registered that more than $80 \%$ of physicians report working through illness (Bracewell et al., 2010; McKevitt et al., 1997; Rosvold \& Bjertness, 2001; Sendén et al., 2013), while being unable to carry out their duties to the best of their ability (Waldron, 1996). This behavior is unlikely to benefit the physicians, their colleagues, or their patients. Presenteeism has been associated with negative personal outcomes, such as decreased general health (Aronsson et al., 2011; Bergström et al., 2009), depression (Conway et al., 2014), burnout (Miraglia \& Johns, 2015; Thun et al., 2014), and future sickness absenteeism (Bergström et al., 2009; Gustafsson \& Marklund, 2011; Hansen \& Andersen, 2009), and with negative organizational outcomes such as decreased performance and productivity (Dellve et al., 2011; Hemp, 2004; Schultz et al., 2009). Presenteeism has also been identified as a risk factor for committing serious errors and safety violations (Niven \& Ciborowska, 2015), and in disease transmission (Widera et al., 2010). To limit presenteeism's role as a health hazard (Widera et al., 2010) and to promote health among physicians and their patients, it is vital to investigate initiatives to decrease this behavior among physicians.

Research has focused on identifying occupational, personal, and work factors in the medical profession that contribute to presenteeism among physicians (Gudgeon et al., 2009; Henderson et al., 2012; McKevitt et al., 1997; Rosvold \& Bjertness, 2001; Sendén et al., 2013; Thompson et al., 2013; Waldron, 1996). An often overlooked aspect is possible societal level antecedents that are the result of welfare benefits such as paid sick leave. The latter is a highly relevant factor, as it aims to facilitate a healthy balance between work, economic loss, and necessary rest and restitution in times of ill health among employees.

Several researchers have emphasized that the broader societal environment affect work conditions and employee's perceptions, attitudes, and behaviors concerning sickness presenteeism (Claes, 2011; Dew et al., 2005; Hansen \& Andersen, 2008; Hansson et al., 2006). Findings from a recent meta-analysis of the correlates of presenteeism show that stricter absence policies were associated with higher presenteeism (Miraglia \& Johns, 2015). A study among Swedish employees found that when insurance systems were more generous, the aggregate number of sick days increased, and when the systems were more austere, the number fell (Henrekson \& Persson, 2004). These results may indicate that employees working in countries with less generous insurance systems replace absenteeism with presenteeism due to economy. Arguably, generous public insurance systems can potentially inhibit sickness presenteeism, while more austere systems are expected to increase sickness presenteeism. If so, it is relevant to investigate if sickness presenteeism scores among European physicians vary according to national legislations concerning paid sick leave.

To classify the welfare regimes of the included countries, we used Bonolis (1997) classification on the degree of social welfare provided and mode of delivery within each 
country as an analytic tool (Hagelund \& Bryngelson, 2014). According to Bonoli (1997), Sweden and Norway have a Nordic welfare state regime with high social expenditure, financed through taxation and designed to prevent poverty for the entire population. Italy has a Southern welfare state regime with low social expenditure, which is financed through earnings-related contributions to provide income maintenance. The International Social Security Association $(2004,2012)$ shows that welfare state regimes vary substantially in their legislation concerning paid sick leave. Despite the many similarities between the Norwegian and Swedish welfare states, their sickness insurance systems have developed differently (Hagelund \& Bryngelson, 2014). Employees in Norway are guaranteed full pay from the first day of illness-related absence. In Sweden, employees are entitled to receive $80 \%$ of wages, with no legal guarantee of pay for the first day of illness-related absence. Italian employees are entitled to receive between 50.0 and $66.7 \%$ of their wages, depending on the length of absence, with no legal guarantee of pay for the first 3 days. No changes in wage replacements levels have occurred in any of these countries between 2005 and 2012 (International Social Security Association, 2004, 2012). If paid sick leave indeed leads to decreased sickness presenteeism among physicians, then it is relevant to investigate whether physicians working in countries with lower economic compensation for illness-related absences report higher rates of presenteeism than those working in countries with more extensive economic compensation.

Research on presenteeism has uncovered a range of demographic variables that potentially influence the decision to work when sick, including gender (Gosselin et al., 2013; Johns, 2010), age (Aronsson \& Gustafsson, 2005; Gosselin et al., 2013), work hours (Bockerman \& Laukkanen, 2010b), and family status (i.e., having children; Aronsson et al., 2000). In addition, type of work has been associated with presenteeism among physicians (Rosvold \& Bjertness, 2001). The social responsibilities found in university hospitals that include patient treatment, teaching, and research (Borges et al., 2010) constitute care demands that affect presenteeism among physicians (Elstad \& Vabø, 2008). Sick leave has also been shown to be more frequent among women, older employees, and single parents (Scheil-Adlung \& Sandner, 2010). On a societal level, the unemployment rate and female employment rate are relevant indicators of the labor market and may influence presenteeism. High unemployment has been related to lower absence rates (Shoss \& Penney, 2012) and may stimulate presenteeism, as it reflects job insecurity (Claes, 2011). As women have a tendency to have higher presenteeism than men (Bockerman \& Laukkanen, 2010a; Leineweber et al., 2011), a high female employment rate may stimulate presenteeism. These demographic variables are important confounders in the association between paid sick leave and presenteeism, as they play a crucial role in reported incidents of paid sick leave across countries (Scheil-Adlung \& Sandner, 2010).

The aim of the current study was to investigate if sickness presenteeism varied according to differences in economic compensation for sick leave among senior consultant physicians working in Sweden, Norway, and Italy. We hypothesized that less economic compensation for illness-related absences from work leads to increased probability of presenteeism. Accordingly, we expected that senior consultant physicians from Italy would report higher scores of sickness presenteeism than senior consultant physicians in Sweden and Norway. Sweden was expected to report higher presenteeism scores than Norway, while Norway was expected to have the lowest scores of the three countries. We also hypothesized that the association between presenteeism and country would remain even after controlled for gender, age, family status, work hours, and work content. 


\section{Method}

\section{Sample}

The sample consisted of senior consultants who participated in phase I (2004-2005) and phase II (2012-2013) in the study of Health and Organization among University Hospital Physicians in Europe (HOUPE). The HOUPE-study is a research program concerning work-related health, organizational culture, career paths, and working conditions among university hospital physicians. We used repeated cross-sectional data from university hospitals in Sweden, Norway, and Italy. The repeated cross-sectional design enables us to analyze aggregated change over time and is commonly used to analyze population or group change (Rafferty et al., 2015).

All permanently and actively working physicians at the three university hospitals were invited to participate in the two phases of date collection. Because of differences in employment status in the three countries, resident physicians were not included in the current study. The study sample consisted of 1326 senior consultant physicians from phase I (Sweden $\mathrm{N}=753$, response rate $=40.0 \%$, Norway $\mathrm{N}=223$, response rate $=50.2 \%$, and Italy $\mathrm{N}=350$, response rate $=41.3 \%$ ) and 1403 senior consultant physicians from phase II (Sweden $\mathrm{N}=735$, response rate $=37.0 \%$, Norway $\mathrm{N}=331$, response rate $=66.7 \%$, and Italy $\mathrm{N}=337$, response rate $=39.4 \%$ ). Nonrespondent analysis of the samples showed a representative response rate based on sex and age in all three countries.

\section{Procedure}

Eligible participants received a written invitation that included information about the purpose of the study, guarantees for their anonymity, and plans for subsequent dissemination of the results. Swedish and Norwegian participants received a letter containing log-on information for accessing a web-based questionnaire at www.houpe.no, hosted in Norway. A paper version of the questionnaire was sent to respondents in Italy, as well as to respondents in Sweden (phase I) and Norway (phase I and II) who were reluctant to respond electronically. The survey used for Swedish and Norwegian participants was conducted in English, and Italian respondents received the questionnaire in Italian. Back-translation (Brislin et al., 1973) between English and Italian was used for the Italian questionnaire. Participation was voluntary and confidentiality was guaranteed. The study was approved by the administrations of each hospital, in addition to the respective national Regional Ethical Boards and data inspectors.

\section{Measures}

\section{Sickness presenteeism}

A single self-reported item measured sickness presenteeism (Rosvold \& Bjertness, 2001; Sendén et al., 2013): 'Have you gone to work with an illness in a situation where you would have recommended a patient to stay at home?' Responses were given on a 5-point scale from Very seldom or never (1) to Very often or always (5).

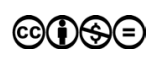




\section{Demographic variables}

Gender, age (under 39, 40-54 years, and 55 years and over), and work hours (employees who work night shifts or on call duty $=1$, employees who do neither $=0$ ) were included as potential confounders in the analysis. To control for respondents' family status, we included civil status (in a relationship $=1$, not in a relationship $=0$ ), partner's employment status (partner in paid employment $=1$, partners not in paid employment $=0$ ), and children (one or more children $=1$, no children $=0$ ). Work content was measured by how much of the respondents' work was taken up by patient care, teaching, research, and management/administration. Response were given in percentages and summed to $100 \%$.

\section{Statistical Analysis}

Cross-country differences in sickness presenteeism were analyzed by analysis of variance (ANOVA). Due to unequal sample sizes, post-hoc comparisons were performed using the Games-Howell test (Field, 2009).

Ordinary linear regression analyses were conducted to adjust for demographic variables and work tasks on the relationship between country and sickness presenteeism. Sickness presenteeism served as the dependent variable, with Italy as the reference category for country. The analyses were conducted with two models. The unadjusted betas were calculated in Model 1. Model 2 adjusted for the demographic variables of gender, age, work hours, family status, and work content (patient care, research, teaching, and management and administration). No multicollinearity between the demographic variables was detected, and the dependent variable was sufficiently normally distributed for use in ordinary linear regression.

To investigate if the variation by country at phase I differs from the variation by country at phase II, we performed a univariate linear regression with sickness presenteeism as the dependent variable and, country, time, and the interaction between country and time as fixed factors. Gender, age, work hours, family status, and work content were covariates.

Differences between country scores of sickness presenteeism between phase I and phase II were tested by independent sample $t$-test.

The statistical software IBM SPSS version 20 was used throughout the analyses.

\section{Results}

Table 1 summarizes a country comparison of welfare state regime, labor market indicators, and registered sick leave by the hospitals included in the current study. Unemployment rate and female employment rate were stable from 2005 to 2012 in all three countries with the exception of the unemployment rate in Italy, which increased from $7.7 \%$ in 2005 to $10.6 \%$ in 2012 . Norway had the highest rate of practicing physicians per 1000 population (4.3), while Italy had the lowest (3.9). Hospital-registered sick leave rates in Sweden $(3.0-2.8 \%)$ and Norway $(3.4-3.7 \%)$ indicate stability between phase I and II. However, we were not able to gain information from Italy because of ethical restrictions by the hospital. 
Table I Characteristics of the three European countries surveyed

\begin{tabular}{lccc}
\hline Indicator & Sweden & Norway & Italy \\
\hline Type of European welfare state regime (Bonoli, 1997) & Nordic & Nordic & Southern \\
Labor market indicators & & & \\
$\quad$ Unemployment rate, 2005/20 I2 (\%) (OECD, 20 I5a) & $7.6 / 8.0$ & $4.5 / 3.2$ & $7.7 / 10.6$ \\
$\quad$ Female employment rate, 2005/20 I2 (\%) (OECD, 20 I5a) & $70.2 / 71.8$ & $71.8 / 73.8$ & $45.5 / 47.1$ \\
$\quad$ Practicing physicians per I000 population in 20 I3 (OECD, 20I5b) & 4.0 & 4.3 & 3.9 \\
Sick leave & & & \\
$\quad$ Registered sick leave by the respective hospitals in 2005/20 I2, (\%) & $3.0 / 2.8$ & $3.4 / 3.7$ & - \\
\hline
\end{tabular}

Table 2 Means, prevalence, standard deviations, and 95\% confidence interval of self-reported sickness presenteeism by country at phases I and II

\begin{tabular}{|c|c|c|c|c|c|c|c|c|c|}
\hline & \multicolumn{4}{|c|}{ Phase I } & \multicolumn{4}{|c|}{ Phase II } & \multirow[t]{2}{*}{$d$} \\
\hline & $\mathrm{n}$ & $M(\%)$ & SD & $95 \% \mathrm{Cl}$ & $n$ & $M(\%)$ & $\mathrm{SD}$ & $95 \% \mathrm{Cl}$ & \\
\hline Sweden & 753 & $3.10_{a}(73)$ & 1.18 & $3.02-3.19$ & 735 & $2.82_{a}(64)$ & 1.17 & $2.74-2.9 \mid$ & .23 *** \\
\hline Norway & 223 & $2.97_{a}^{a}(74)$ & 1.07 & $2.83-3.11$ & 331 & $3.06_{b}(76)$ & 1.04 & $2.95-3.18$ & n.s. \\
\hline Italy & 350 & $3.37_{b}(86)$ & 1.06 & $3.25-3.48$ & 337 & $3.14_{b}(79)$ & 1.13 & $3.02-3.26$ & $.20 *$ \\
\hline
\end{tabular}

Note: Between-country differences are marked with different subscripts. Within-country differences between phase I and phase II were tested using the Student's t-test. $d=$ Cohen's $d ; n=$ sample in each country; $\mathrm{M}=$ mean; $(\%)$ = percentage of the respondents who sometimes or often had gone to work while ill; $\mathrm{SD}=$ standard deviation; $\mathrm{Cl}=$ confidence interval; n.s. = not significant.

* $p<.01$, *** $p<.001$

Table 2 provides an overview of mean scores, prevalence, standard deviations, and $95 \%$ confidence intervals of sickness presenteeism in Sweden, Norway, and Italy. Italian respondents had the highest mean score of presenteeism in both phases of the study. Norway had the lowest mean score at phase I, while Sweden had the lowest mean score at phase II. To compare our results with other studies, the prevalence of sickness presenteeism was computed, defined as those who indicate that they sometimes or often went to work while ill (phase I: Sweden $=73 \%$, Norway $=74 \%$, and Italy $=86 \%$; phase II: Sweden $=64 \%$, Norway $=76 \%$, and Italy $=79 \%)$. Country differences in reported sickness presenteeism were indicated by inspection of $95 \%$ confidence intervals, and were confirmed at both phase I, F $(2,1323)=9.89, p<.001, \omega=.12$, and phase II, $\mathrm{F}$ $(2,1400)=11.08, p<.001 \omega=.12$. The observed effect sizes were considered small (Cohen, 1992). A test of the within-country differences between the two phases showed that Sweden and Italy reported significantly lower scores of sickness presenteeism at phase II.

At phase I, the Games-Howells post-hoc test revealed that Italy had significantly higher scores of sickness presenteeism than Sweden $(p<.001)$ and Norway $(p<.001)$. Even though Sweden did report higher presenteeism scores than Norway, the difference was not significant. At phase II, the higher scores of presenteeism in Italy were significant 
Table 3 Country as a predictor of sickness presenteeism at phase I and phase II

\begin{tabular}{|c|c|c|c|c|c|c|c|c|}
\hline & \multicolumn{4}{|c|}{ Phase I } & \multicolumn{4}{|c|}{ Phase II } \\
\hline & $\beta$ & $p$ & $95 \% \mathrm{Cl}$ & $\Delta \mathrm{R}^{2}$ & $\beta$ & $p$ & $95 \% \mathrm{Cl}$ & $\Delta R^{2}$ \\
\hline Model I & & & & .02 & & & & .03 \\
\hline \multicolumn{9}{|l|}{$\begin{array}{l}\text { Country } \\
\text { Italy (ref) }\end{array}$} \\
\hline Sweden & -0.12 & .00 & -0.43 to -0.10 & & -0.20 & .00 & -0.66 to -0.25 & \\
\hline Norway & -0.15 & .00 & -0.68 to -0.25 & & -0.05 & .23 & -0.37 to 0.09 & \\
\hline Model 2 & & & & .03 & & & & .06 \\
\hline \multicolumn{9}{|l|}{$\begin{array}{l}\text { Country } \\
\text { Italy (ref) }\end{array}$} \\
\hline Sweden & -0.12 & .00 & -0.45 to -0.11 & & -0.21 & .00 & -0.7 I to -0.27 & \\
\hline Norway & -0.14 & .00 & -0.64 to -0.19 & & -0.05 & .31 & -0.37 to 0.12 & \\
\hline Gender (ref men) & 0.12 & .00 & 0.14 to 0.44 & & 0.17 & .00 & 0.23 to 0.53 & \\
\hline \multicolumn{9}{|l|}{ Age } \\
\hline \multicolumn{9}{|l|}{ Under 40 (ref) } \\
\hline From 40 to 54 & 0.07 & .13 & -0.05 to 0.39 & & -0.03 & .56 & -0.27 to 0.15 & \\
\hline 55 and over & 0.06 & .23 & -0.10 to 0.40 & & 0.05 & .25 & -0.10 to 0.36 & \\
\hline Night shift and/or call duty & 0.03 & .40 & -0.10 to 0.25 & & 0.04 & .27 & -0.08 to 0.28 & \\
\hline In a relationship & 0.00 & .98 & -0.53 to 0.52 & & 0.06 & .14 & -0.12 to 0.85 & \\
\hline Partner works & -0.02 & .53 & -0.33 to 0.17 & & 0.01 & .82 & -0.25 to 0.32 & \\
\hline Have children & -0.02 & .45 & -0.31 to 0.14 & & -0.05 & .11 & -0.48 to 0.05 & \\
\hline \multicolumn{9}{|l|}{ Work content } \\
\hline Patient care & 0.13 & .08 & $0.00-0.01$ & & 0.03 & .55 & $0.00-0.01$ & \\
\hline Research & 0.04 & .41 & $0.00-0.01$ & & 0.10 & .01 & $0.00-0.01$ & \\
\hline $\begin{array}{l}\text { Management } \\
\text { administration }\end{array}$ & 0.12 & .05 & $0.00-0.01$ & & 0.04 & .38 & $0.00-0.01$ & \\
\hline Teaching & 0.06 & .19 & $0.00-0.02$ & & 0.06 & .11 & $0.00-0.02$ & \\
\hline
\end{tabular}

Note: $\beta$ = standardized beta $C l=$ confidence interval; $\Delta R^{2}=$ adjusted $R$ square; $p=p$ value, and is considered significant at $p<.05$.

when compared to Sweden $(p<.001)$, but not significant when compared to Norway. Sweden had significantly lower scores of sickness presenteeism than Norway $(p<.01)$ at phase II.

The regression analyses at phase I (Tab. 3) show that Sweden and Norway had significant lower mean values than Italy in both Model 1 and Model 2. At phase II, the beta values were significant for Sweden and not significant for Norway in both Model 1 and Model 2. Of the control variables, gender was significant in both phase I and II, and doing research was significant at phase II.

The univariate linear regression showed a significant effect of both country, time, and their interaction $(p<.004$ in Model 1 and $p<.001$ in Model 2). An illustration of the difference between country mean scores of sickness presenteeism at the two phases is shown in Fig. 1. 
Figure I Marginal means of sickness presenteeism by country and time.

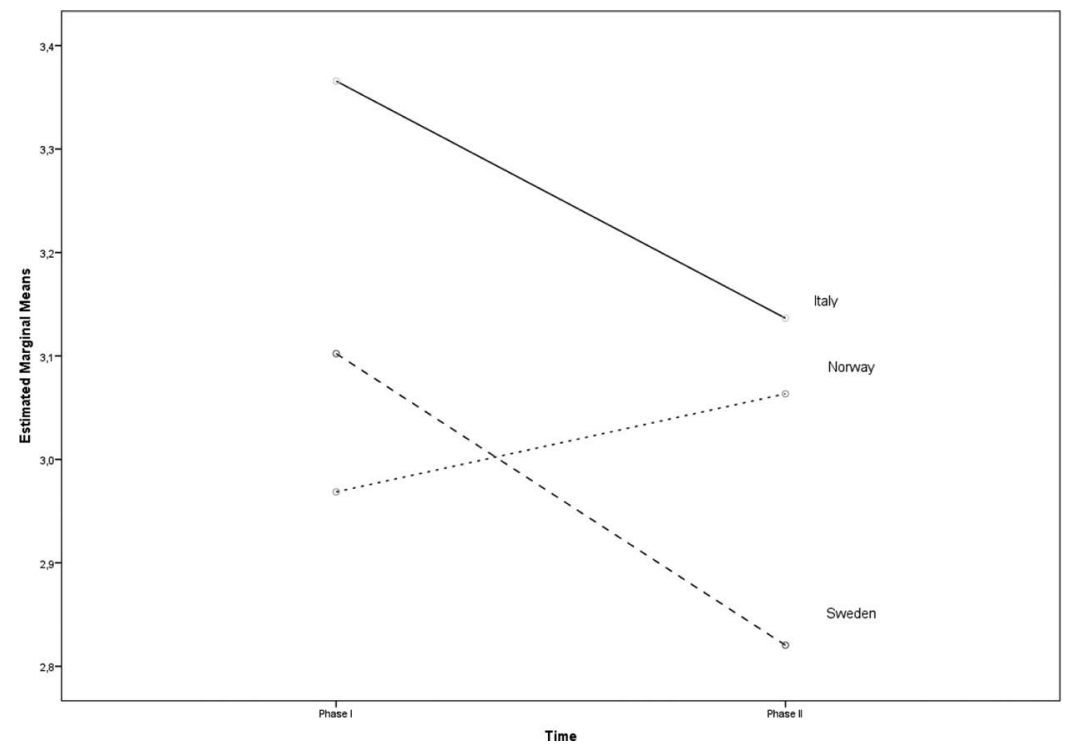

\section{Discussion}

This two-phased cross-sectional study has shown that, in a sample of senior consultant physicians employed at university hospitals in Sweden, Norway, and Italy, sickness presenteeism scores did, to some extent, vary in accordance with national policies on paid sick leave. The prevalence of presenteeism in the current study corresponds to similar studies that report that up to $80 \%$ of physicians work while ill (Bracewell et al., 2010; McKevitt et al., 1997; Rosvold \& Bjertness, 2001; Sendén et al., 2013; Waldron, 1996). The current results also show there were country differences in presenteeism among senior consultants. The results partly support our main hypothesis that countries with higher economic compensation for illness-related absences, such as Scandinavian countries, have lower scores of presenteeism than countries with less economic compensation, such as Italy. However, the difference in presenteeism scores between the three countries at phase I varied from the difference at phase II, despite there being no changes in wage replacement covered by the national insurance system in each country in the same period (International Social Security Association, 2004, 2012). The current results can reflect changes in the labor market in the countries of the physicians participating in the current study. Although Italy increased its unemployment rate, both general unemployment rate and female employment rate were stable in the Scandinavian countries from phase I to phase II (OECD, 2015a). Presenteeism can be a manifestation of job insecurity in periods of high unemployment rate. However, reported presenteeism decreased in a period of higher prevalence of unemployment in Italy, and decreased in Sweden in the same period. Accordingly, it might be more relevant to explain these changes in terms of important system factors that could be influential for the professional group within each hospital. 
After the initial data collection of the HOUPE-study in 2005, the Swedish host hospital introduced an intervention project in 2006 that used survey feedback seminars to initiate organizational change (Fridner et al., 2014). Altogether, 20 feedback seminars were conducted and 250 physicians participated in these meetings, which aimed to improve physicians' health and work satisfaction. These seminars were regarded as successful, as they achieved acceptance for organizational change and may have influenced pressure to attend among the physicians (unpublished data).

In Italy, a recent debate concerning medical liability (Motta \& Nappi, 2014) and the high costs of the criminal proceedings related to medical malpractice (Traina, 2009) has been prominent in the national arena. The debate has resulted in physicians' increasingly practicing defensive medicine (Traina, 2009). As physicians become more defensive so as to avoid potential litigation, they may also become more cautious of going to work while ill, as this may increase the risk of making mistakes. Recently, the Italian parliament approved a new law that includes physicians in the right to at least 11 hours of rest after a 24 hours shift [Law of 30 October 2014 (Legge 30 ottobre 2014)]. The ongoing debate that occurred in the lead up to this legislation may have influenced the physician's behavior in this study, and reduced the observed presenteeism scores of Italian physicians.

Of the control variables included in the current study, gender and conducting research made a significant contribution in the models. Women had higher sickness presenteeism than men in both phases of the study, which is parallel with earlier findings (Aronsson \& Gustafsson, 2005; Gosselin et al., 2013). Conducting research was associated with increased sickness presenteeism among physicians included in the current study. The competing responsibilities of research, teaching, and clinical work represent a difficult demand for all clinical academics (Conrad et al., 2010), which could fortify higher attendance pressure. The results of the current study may indicate that conducting research represents a demand that pressures physicians to work while ill.

When interpreting the results from this study, it is important to keep in mind that our sample consisted of senior consultants working at university hospitals. The situation may be different for physicians working in private practice (Rosta et al., 2014; Rosvold \& Bjertness, 2001), or for other health care professionals working under different working conditions. A high prevalence of presenteeism has not only been reported among physicians, but also in other occupations in the health and welfare services as well (Aronsson et al., 2000). As physicians may be regarded as financially privileged, the impact of the financial aspects of paid sick leave may be of greater importance in occupational groups in the health and welfare services, where average earnings are lower. Aronsson et al. (2000) investigated sickness presenteeism in relation to occupation and personal income among employees in Sweden. Contrary to their findings that those with the lowest monthly income were more likely to attend work while ill, medical doctors was the only occupation that manifested high monthly income and high sickness presenteeism. This can reflect that having the economic resources and work stability to support the current standard of living in the foreseeable future is equally as important for physicians as it is for the rest of the workforce. The extensive negative consequences of presenteeism among physicians, referred to in the introduction of this paper, underpin the importance of investigating potential factors that may reduce such behavior.

Future research in the domain of presenteeism is recommended, including further investigation of differences in national insurance systems and how changes in these 
systems are reflected in employee behavior. As discussed, there are a range of aspects in the higher structural environment that may influence whether and how workers change their behavior. Longitudinal studies that track the development of national insurance policies together with measures of sickness presenteeism would be of high relevance to understand how the social structures of welfare systems affect employee behavior. An obstacle to performing such international cross-country comparisons is the complete lack of international databases measuring sickness presenteeism (Claes, 2011).

With regard to hospital physicians, research on ways to reduce the high prevalence of presenteeism is still highly relevant. As physicians from Norway (who are fully paid when sickness absent) and physicians from Italy (who first after 3 days of absence receive between 50 and $66.7 \%$ of their wage after the first 3 days of absence) both report high levels of sickness presenteeism, paid sick leave alone may not explain the high prevalence of presenteeism among physicians. Paid sick leave is an important tool for society to sustain the productivity of its human resources, by enabling workers to access medical care and follow the recommended treatment to facilitate faster recovery and illness prevention. However, factors other than economic compensation may have greater influence on presenteeism behaviors among hospital physicians. Concern over patient care (Gudgeon et al., 2009), difficulties in arranging cover (McKevitt et al., 1997), and the role identity that physicians are invincible (Henderson et al., 2012; Thompson et al., 2013) may all be challenges that are inherent to the work environment and may influence presenteeism.

\section{Strengths and Limitations}

This study contributes to the existing literature by investigating the relationship between sickness presenteeism and paid sick leave in an occupation that has shown to have a high prevalence of sickness presenteeism worldwide. The major strength of this study was the repeated cross-sectional design and the inclusion of countries with various paid sick leave policies. Nevertheless, there are several limitations to account for while interpreting the results of this study. The current results derived from cross-sectional data rely on self-reported data, and were thus not oriented toward causality but rather toward variations in sickness presenteeism. With regard to the use of self-reported data, it is difficult to use other measures of sickness presenteeism because only the individual knows if he or she is sickness present or not (Claes, 2011; Johns, 2011).

However, one must be cautious in generalizing the study findings, as the sample consists of senior consultants. In contrast, residents are employed in an educational position and are less economically robust than their senior colleagues. Therefore, residents may be more prone to sickness presenteeism, as they are more exposed to the economical consequence of absence. There may also be structural factors or processes in each hospital not accounted for in the current study that may affect sickness presence. As the welfare system constitutes an important facilitator for all ill workers within a country, regardless of profession, these results could be relevant to other occupations. However, one must be cautious in generalizing cross-sectional data, as there can be systematic differences in presenteeism rates between sectors and occupations within a country (Aronsson et al., 2000). Research investigating occupational differences in the relative importance of sickness benefits within each country can be relevant in future discussions and decisions about national benefit schedules.

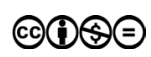


Another limitation is that sickness presenteeism was measured with a single-item question, asking if the physicians had gone to work with an illness they would have recommended a patient to stay at home. However, in some cases, single-item questions are appropriate measures to use (DeSalvo et al., 2006). Our question differed from that of other studies in that our question was not limited to a defined period of 6 or 12 months (e.g., Aronsson et al., 2000), and it thus forced physicians to consider themselves as patients and better relate to situations where they would have recommended patients to take sick leave (Sendén et al., 2013). Arguably, the question that was used applied more to the specific context of physicians than those of earlier studies.

Cultural differences on how legitimate it is to be absent from work have also shown differences between countries (Addae et al., 2013), and are not accounted for in this study. However, we asked a question on presenteeism that forced the physicians to answer concerning a common context (i.e., in which they would have recommended their patient to stay home from work). Consequently, the symptoms that the physicians reported as presenteeism in this study were severe enough to be entitled to sickness certificates.

\section{Conclusion}

Sickness presenteeism is prevalent among physicians, and the need to investigate initiatives to reduce presenteeism among physicians is evident, due to its harmful consequences. In this regard, paid sick leave is a relevant factor for potentially reducing presenteeism. However, other pieces of legislations, such as workhours and medical liability, may also influence how employees think about sickness presenteeism. To reduce the high prevalence of harmful presenteeism among physicians, it is important further to investigate potential social initiatives including national schedules for welfare benefit.

\section{Acknowledgment}

No funding was received for this publication.

The authors declare that there is no conflict of interest.

\section{References}

Addae, H. M., Johns, G. \& Boies, K. (2013). The legitimacy of absenteeism from work: a nine nation exploratory study. Cross Cultural Management: An International Journal, 20: 402-428. doi: http://dx.doi.org/10.1108/CCM-05-2012-0040.

Aronsson, G. \& Gustafsson, K. (2005). Sickness presenteeism: Prevalence, attendance-pressure factors, and an outline of a model for research. Journal of Occupational and Environmental Medicine, 47: 958-966. doi: http://dx.doi.org/10.1097/01.jom.0000177219.75677.17.

Aronsson, G., Gustafsson, K. \& Dallner, M. (2000). Sick but yet at work. An empirical study of sickness presenteeism. Journal of Epidemiology and Community Health, 54: 502-509. doi: http://dx.doi.org/10.1136/jech.54.7.502.

Aronsson, G., Gustafsson, K. \& Mellner, C. (2011). Sickness presence, sickness absence, and self-reported health and symptoms. International Journal of Workplace Health Management, 4: 228-234. doi: http://dx.doi.org/10.1108/17538351111172590. 
Bergström, G., Bodin, L., Hagberg, J., Aronsson, G. \& Josephson, M. (2009a). Sickness Presenteeism Today, Sickness Absenteeism Tomorrow? A Prospective Study on Sickness Presenteeism and Future Sickness Absenteeism. Journal of Occupational and Environmental Medicine, 51: 629-638. doi: 10.1097/JOM.0b013e3181a8281b.

Bergström, G., Bodin, L., Hagberg, J., Lindh, T., Aronsson, G. \& Josephson, M. (2009b). Does sickness presenteeism have an impact on future general health? International Archives of Occupational and Environmental Health, 82: 1179-1190. doi: 10.1007/s00420-0090433-6.

Bockerman, P. \& Laukkanen, E. (2010a). Predictors of Sickness Absence and Presenteeism: Does the Pattern Differ by a Respondent's Health? Journal of Occupational and Environmental Medicine, 52: 332-335.doi: http://dx.doi.org/10.1097/JOM.0b013e3181d2422f.

Bockerman, P. \& Laukkanen, E. (2010b). What makes you work while you are sick Evidence from a survey of workers. European Journal of Public Health, 20: 43-46. doi: http:// dx.doi.org/10.1093/eurpub/ckp076.

Bonoli, G. (1997). Classifying welfare states: a two-dimension approach. Journal of social policy, 26: 351-372. Borges, N. J., Navarro, A. M., Grover, A. \& Hoban, J. D. 2010. How, When, and Why Do Physicians Choose Careers in Academic Medicine? A Literature Review. Academic Medicine, 85, 680-686. doi: http://dx.doi.org/10.1017/ S0047279497005059.

Bracewell, L. M., Campbell, D. I., Faure, P. R., Giblin, E. R., Morris, T. A., Satterthwaite, L. B., Simmers, C. D., Ulrich, C. M. \& Holmes, J. D. (2010). Sickness presenteeism in a New Zealand hospital. Journal of the New Zealand Medical Association, 123. URL: http:// search.proquest.com/docview/1034260234? accountid=12870.

Brislin, R. W., Lonner, W. J. \& Thorndike, R. M. (1973). Cross-cultural research methods, New York, John Wiley.

Claes, R. (2011). Employee correlates of sickness presence: A study across four European countries. Work and Stress, 25: 224-242. doi: http://dx.doi.org/10.1080/02678373.20 11.605602 .

Cohen, J. (1992). Quantitative methods in psychology. A power primer. Psychological Bulletin, 112: 155-159. doi: http://dx.doi.org/10.1037/0033-2909.112.1.155.

Conway, P. M., Hogh, A., Rugulies, R. \& Hansen, Å. M. (2014). Is Sickness Presenteeism a Risk Factor for Depression? A Danish 2-Year Follow-Up Study. Journal of Occupational and Environmental Medicine, 56: 595-603. doi: http://dx.doi.org/10.1097/ JOM.0000000000000177.

Dellve, L., Hadzibajramovic, E. \& Ahlborg, G. (2011). Work attendance among healthcare workers: prevalence, incentives, and long-term consequences for health and performance. Journal of advanced nursing, 67: 1918-1929. doi: http://dx.doi.org/10.1111/j.13652648.2011.05630.x.

Desalvo, K. B., Fisher, W. P., Tran, K., Bloser, N., Merrill, W. \& Peabody, J. (2006). Assessing measurement properties of two single-item general health measures. Quality of Life Research, 15: 191-201. doi: http://dx.doi.org/10.1007/s11136-005-0887-2.

Dew, K., Keefe, V. \& Small, K. (2005). 'Choosing' to work when sick: workplace presenteeism. Social Science \& Medicine, 60: 2273-2282. doi: http://dx.doi.org/10.1016/j. socscimed.2004.10.022.

Elstad, J. I. \& Vabø, M. (2008). Job stress, sickness absence and sickness presenteeism in Nordic elderly care. Scandinavian Journal of Public Health, 36: 467-474. doi: http://dx.doi. org/10.1177/1403494808089557.

Field, A. (2009). Dicovering statistics using SPSS: (and sex and drugs and rock ' $n$ ' roll, Los Angeles, SAGE.

Fridner, A., Pingel, B., Løvseth, L. T., Sendén, M. G. \& Schenck-Gustafsson, K. (2014). From Awareness to Action Using the Survey Feedback Method. Journal of Health 
Science, 2: 325-329. URL: http://www.davidpublishing.com/davidpublishing/Upfile/11/9/2014/2014110985676817.pdf.

Gosselin, E., Lemyre, L. \& Corneil, W. (2013). Presenteeism and absenteeism: differentiated understanding of related phenomena. Journal of Occupational Health Psychology, 18: 75-86. doi: http://dx.doi.org/10.1037/a0030932.

Gudgeon, P., Wells, D. A., Baerlocher, M. O. \& Detsky, A. S. (2009). Do you come to work with a respiratory tract infection? Occupational and Environmental Medicine, 66: 424424. doi: http://dx.doi.org/10.1136/oem.2008.043927.

Gustafsson, K. \& Marklund, S. (2011). Consequences of sickness presence and sickness absence on health and work ability: a Swedish prospective cohort study. International Journal of Occupational Medicine and Environmental Health, 24: 153-165. doi: http:// dx.doi.org/10.2478/s13382-011-0013-3.

Hagelund, A. \& Bryngelson, A. (2014). Change and resilience in welfare state policy. The politics of sickness insurance in Norway and Sweden. Social Policy \& Administration, 48: 300-318. doi: http://dx.doi.org/10.1111/spol.12009.

Hansen, C. D. \& Andersen, J. H. (2008). Going ill to work - What personal circumstances, attitudes and work-related factors are associated with sickness presenteeism? Social Science \& Medicine, 67: 956-964. doi: http://dx.doi.org/10.1016/j.socscimed.2008.05.022.

Hansen, C. D. \& Andersen, J. H. (2009). Sick at work-a risk factor for long-term sickness absence at a later date? Journal of Epidemiology and Community Health, 63: 397-402. doi: http://dx.doi.org/10.1136/jech.2008.078238.

Hansson, M., Bostrom, C. \& Harms-Ringdahl, K. (2006). Sickness absence and sickness attendance - What people with neck or back pain think. Social Science \& Medicine, 62: 2183-2195. doi: http://dx.doi.org/10.1016/j.socscimed.2005.10.002.

Hemp, P. (2004). Presenteeism: At work - but out of it. Harvard Business Review, 82: 49-58. URL: http://www.npg-rsp.ch/fileadmin/npg-rsp/Themen/Fachthemen/Hemp 2004 Presenteeism.pdf.

Henderson, M., Brooks, S. K., Del Busso, L., Chalder, T., Harvey, S. B., Hotopf, M., Madan, I. \& Hatch, S. (2012). Shame! Self-stigmatisation as an obstacle to sick doctors returning to work: a qualitative study. BMJ open, 2: e001776. doi: 10.1136/bmjopen-2012-001776.

Henrekson, M. \& Persson, M. (2004). The effects on sick leave of changes in the sickness insurance system. Journal of Labor Economics, 22: 87-113. doi: http://dx.doi. org $/ 10.1086 / 380404$.

Heymann, J., Rho, H. J., Schmitt, J. \& Earle, A. (2010). Ensuring a healthy and productive workforce: comparing the generosity of paid sick day and sick leave policies in 22 countries. International Journal of Health Services, 40: 1-22. doi: http://dx.doi.org/10.2190/ HS.40.1.a.

International Social Security Association 2004. Social Security Programs Throughout the World: Europe (2004). Social Security Programs Throughout the World. Washington, DC. URL: https://www.issa.int/en GB/ssptw.

International Social Security Association 2012. Social Security Programs Throughout the World: Europe (2012). Social Security Programs Throughout the World. Washington, DC. URL: https://www.issa.int/en GB/ssptw.

Johns, G. (2010). Presenteeism in the workplace: A review and research agenda. Journal of Organizational Behavior, 31: 519-542. doi: http://dx.doi.org/10.1002/job.630.

Johns, G. (2011). Attendance Dynamics at Work: The Antecedents and Correlates of Presenteeism, Absenteeism, and Productivity Loss. Journal of Occupational Health Psychology, 16: 483-500. doi: http://dx.doi.org/10.1037/a0025153.

Law of 30 October [Legge 30 Ottobre] (2014). Gazzetta Ufficiale, n. 161, art. 14. URL: http://www.gazzettaufficiale.it/eli/id/2014/11/10/14G00174/sg. 
Leineweber, C., Westerlund, H., Hagberg, J., Svedberg, P., Luokkala, M. \& Alexanderson, K. (2011). Sickness presenteeism among Swedish police officers. Journal of Occupational Rehabilitation, 21: 17-22. doi: http://dx.doi.org/10.1007/s10926-010-9249-1.

Lovell, V. (2004). No time to be sick: Why everyone suffers when workers don't have paid sick leave. Washington, DC: Institute for Women's Policy Research. URL: http://paidsickdays.nationalpartnership.org/site/DocServer/No Time To Be Sick.pdf.

Mckevitt, C., Morgan, M., Dundas, R. \& Holland, W. W. (1997). Sickness absence and 'working through' illness: a comparison of two professional groups. Journal of Public Health Medicine, 19: 295-300. doi: http://dx.doi.org/10.1093/oxfordjournals.pubmed. a024633.

Miraglia, M. \& Johns, G. (2015). Going to Work Ill: A Meta-Analysis of the Correlates of Presenteeism and a Dual-Path Model. Journal of Occupational Health Psychology: No Pagination Specified. doi: http://dx.doi.org/10.1037/ocp0000015.

Motta, S. \& Nappi, S. (2014). Current trends for medico-legal disputes related to functional nasal surgery in Italy. Acta Otorhinolaryngologica Italica, 34: 210. URL: http://www. ncbi.nlm.nih.gov/pmc/articles/PMC4035843/.

Niven, K. \& Ciborowska, N. (2015). The hidden dangers of attending work while unwell: A survey study of presenteeism among pharmacists. International Journal of Stress Management, 22: 207-221. doi: http://dx.doi.org/10.1037/a0039131.

OECD (2015a). Labour: Labour market statistics. Main Economic Indicators. URL: http:// dx.doi.org/10.1787/data-00046-en.

OECD (2015b). Health at a Glance 2015: OECD Indicators, OECD Publishing, Paris. doi: 10.1787/health glance-2015-en.

Rafferty, A., Walthery, P., \& King-Hele, S. (2015). Analysing change over time: repeated cross-sectional and longitudinal data. Retrieved from University of Essex and University of Manchester. URL: https://www.ukdataservice.ac.uk/media/455362/changeovertime. pdf.

Rosta, J., Tellnes, G. \& Aasland, O. G. (2014). Differences in sickness absence between self-employed and employed doctors: a cross-sectional study on national sample of Norwegian doctors in 2010. BMC health services research, 14: 199. doi: http://dx.doi. org/10.1186/1472-6963-14-199.

Rosvold, E. O. \& Bjertness, E. (2001). Physicians who do not take sick leave: hazardous heroes? Scandinavian Journal of Public Health, 29: 71-75. doi: http://dx.doi.org/10.1177/ 14034948010290010101.

Scheil-Adlung, X. \& Sandner, L. (2010). The case for paid sick leave. Background paper. World Health Organization. URL: http://cdrwww.who.int/healthsystems/topics/financing/healthreport/SickleaveNo9FINAL.pdf.

Schultz, A. B., Chen, C.-Y. \& Edington, D. W. (2009). The cost and impact of health conditions on presenteeism to employers: a review of the literature. Pharmacoeconomics, 27: 365-378. doi: http://dx.doi.org/10.2165/00019053-200927050-00002.

Sendén, M. G., Lovseth, L. T., Schenck-Gustafsson, K. \& Fridner, A. (2013). What makes physicians go to work while sick: a comparative study of sickness presenteeism in four European countries (HOUPE). Swiss Medical Weekly, 143. doi: 10.4414/ smw.2013.13840.

Shoss, M. K. \& Penney, L. M. (2012). The economy and absenteeism: a macro-level study. Journal of Applied Psychology, 97: 881. doi: http://dx.doi.org/10.1037/a0026953.

Thompson, N., Corbett, S. \& Welfare, M. (2013). A qualitative study of how doctors use impression management when they talk about stress in the UK. International Journal of Medical Education, 4: 236-246. URL: http://dx.doi.org/10.5116/ijme.5274.f445.

Thun, S., Fridner, A., Minucci, D. \& Løvseth, L. T. (2014). Sickness present with signs of burnout: The relationship between burnout and sickness presenteeism among university 
hospital physicians in four European countries. Scandinavian Psychologist, 1. doi: http:// dx.doi.org/10.15714/scandpsychol.1.e5.

Traina, F. (2009). Medical malpractice: the experience in Italy. Clinical orthopaedics and related research, 467: 434-442. doi: http://dx.doi.org/10.1007/s11999-008-0582-z.

Waldron, H. A. (1996). Sickness in the medical profession. Annals of Occupational Hygiene, 40: 391-396. doi: http://dx.doi.org/10.1016/0003-4878(96)00027-0.

Widera, E., Chang, A. \& Chen, H. L. (2010). Presenteeism: A Public Health Hazard. Journal of General Internal Medicine, 25: 1244-1247. doi: http://dx.doi.org/10.1007/s11606010-1422-x. 